\title{
"Navigating Change": A Voyage to Connect Science and Culture with Health
}

\author{
Cherie Shehata $^{1}$, Na'alehu Anthony ${ }^{2}$, and Gregory G. Maskarinec ${ }^{3}$ \\ ${ }^{1}$ University of Hawai'i, John A. Burns School of Medicine \\ ${ }^{2}$ Polynesian Voyaging Society \\ ${ }^{3}$ The Physician Center at Mililani
}

\begin{abstract}
Hawai'i faces serious health problems, with average morbidity and mortality rates in key indicators often higher than their mainland counterparts. Much of this relates to poor dietary intake and inadequate physical activity. Many health initiatives have tried to address this issue. This paper examines a unique approach that integrates the health of the land and ecosystem with the health of the people who live in it. We discuss "Navigating Change," a program that brings together students, scientists and culture experts to address the health of the ecosystem, and demonstrate its relation to how we can live healthier lives. Health practitioners are encouraged to 1 ) understand the scope of the need; 2) increase and utilize resources; and 3) incorporate cultural healing in their practice.
\end{abstract}

(C) 2005 Californian Journal of Health Promotion. All rights reserved.

Keywords: Hawaiian voyaging, health education, ecology, cultural healing

\section{Introduction}

Hawaiian history is long and rich, and because of the isolation of its islands it has developed unique ecologic and cultural characteristics. The indigenous people of Hawai'i lived centuries isolated from western influence. They traversed thousands of miles of ocean to reach neighboring islands, living off the land and sea. It is known that they ate a healthy balanced diet, with moderate carbohydrate intake and a low fat diet (Shintani, Beckham, Brown, and O'Conner, 2001).

Over the past two centuries Hawai'i has been part of a dramatic global change due to industrialization and Westernization of many aspects of life. In 1778, Captain James Cook "discovered" the Hawaiian Islands, bringing scourges that would kill many Hawaiian people and native species (Hope, 2003). With the introduction of the ships came, along with other animals, rats and insects that harbored disease and infection, that found many of the plants and animals in Hawai'i defenseless. The introduction of infectious diseases and introduced species was devastating. Ecologically, Hawai'i's previous isolation resulted in the evolution of many species of plants, insects and animals that evolved in the absence of predators (Hope and Hope, 2003). Some endemic bird species were wiped out by diseases like avian malaria, leaving other species endangered (Shehata, Freed, Cann, 2001). This is particularly devastating because many species have co-evolved and are codependant on each other's existence. Hawai'i now leads the world in the number of endangered species (Rauzon, 2001).

Native Hawaiian people were also exposed to many diseases harbored by the sailors who came to Hawai'i from Europe and America (Hope, 2003). These exposures led to widespread devastation and death of great numbers of Hawaiians (Hope, 2003). At the time when Captain Cook became the first Westerner to see Hawai'i, there may have been as many as one million people living in the Hawaiian Islands. In only fifty short years the Hawaiian population plummeted to a mere 200,000 because of the diseases brought by those first ships (Kame'eleihiwa, 1992). Many of the ways by which Native Hawaiians lived also changed. High fat diets, to which no one was accustomed, were introduced (Shintani, 2001). With the 
increase of fat in the diet, and decreasing physical activity, many chronic medical conditions that could have been prevented became prevalent (Shintani, 2001).

In particular, Native Hawaiians have one of the highest rates of obesity in the US (Shintani, 2001). Native Hawaiians also have the highest mortality rates from associated diseases like diabetes, stroke and cardiovascular disease (Shintani, 2001). Health in Hawai'i has been clearly summarized in a recent report by the Department of Health- State of Hawaii, in 2004 (Healthy Hawai'i Initiative, 2004). It is reported that $17.1 \%$ are obese, $79.6 \%$ eat little fruit, and $21 \%$ are smokers. Stroke deaths in Hawai'i are 64.7 per 100,000 , when compared to 56.3 per 100,000 throughout the U.S. Hawai'i also has a high rate of coronary heart disease death, with 113.1 per 100,000 , and $5.8 \%$ of our population suffer from diabetes (Hawai'i Health Initiative, 2004). The difficulty in managing obesity and co-morbid conditions is that they are often multi-faceted in cause (Tiara, Gronley, and Ching, 2004). At this time obesity is the second leading cause of premature death in the US (Halm and Franke, 2004).

\section{Ecology of the Main Hawaiian Islands and the Northwestern Hawaiian Islands (NWHI)}

The NWHI have been in active formation over the past 80 million years (NOAA, 2003). From a stationary hot spot on the earth's mantel, magma has risen to form the volcanic islands (NOAA, 2003). The Pacific plate moves in a northwestern direction, separating the islands (NOAA, 2003). As time passes these islands continue to move in the northwestern direction, eroding and eventually forming reefs, lagoons, and atolls (NOAA, 2003). The NWHI stretch from Nihoa which is 120 miles west of Ni'ihau, to the last atoll Kure, totaling a distance of 1200 miles. They are so small that they are rarely drawn on maps; usually only Midway Atoll is recognized, because of its importance in World War II (Rauzon, 2001).

The NWHI are home to $70 \%$ of the US's coral reefs (NOAA, 2003). The NWHI are the most isolated islands in the world, with North America about 2500 miles away and Asia about
3800 miles away (Rauzon, 2001). Any plant, animal or insect that arrived to Hawai'i had to travel great distances to reach these atolls and Basalt rocks, and once they did they adapted to different niches (Rauzon, 2001). Over millions of years these species evolved and adapted into unique creatures. With the arrival of the first people to the islands there needed to be further adjustment, and indeed some species were lost, but overall Hawaiians lived in relative harmony with their environment. Hawaiians believe that they are genealogically connected to the kalo (taro) plant. It is their older sibling and therefore should be respected and honored along with the land, sky, and water that nourish it. The practice of malama'aina (caring for the land) was the kuleana (responsibility) of all Hawaiians because they understood that caring for the land and everything on it was like caring for a family member. It was also understood that this harmony would allow for the land to in turn care for them.

Through the foresight of some, steps are being taken to help to preserve what resources we have and improve the health of the ecosystem and people. President Theodore Roosevelt in 1909 established a protected area for Hawai'i's birds, the Hawaiian Islands Bird Reservation in the NWHI, which was later changed to Hawaiian Islands National Wildlife Refuge by President Franklin D Roosevelt in 1940 (Rauzon, 2001). In these islands, a refuge currently being managed by several agencies including the US Fish and Wildlife Services (FWS), we have a marker of what the main Hawaiian Islands should be like. It is here that many of Hawai'i's endemic species seek refuge, one of the last spots that they hold onto for survival. To compare the health of the main islands an important bio-marker is the area's apex predators, those animals that are at the top of the food chain. On the main Hawaiian Islands the apex predators are only $3 \%$, whereas in the NWHI they compromise $54 \%$ of the biomass, a drastic disparity (NOAA, 2003).

\section{Navigating Change: Integrating Culture and Ecology with Health}

The Polynesian Voyaging Society (PVS) was founded in 1973 to investigate how Polynesian 
voyagers could have found and inhabited almost every island in the Pacific, centuries before the great European voyages began in the 16th century. PVS set out to prove that Hawai'i was not settled accidentally, as some scholars then believed. They asserted that the voyages to different islands were calculated and that Polynesians were capable of sailing great distances without the use of western instruments (Finney, 1994). PVS set out to prove this theory and built a performance accurate Polynesian canoe, Hokule'a. The goal was retrace the traditional migratory routes that were held in oral traditions throughout the Pacific for thousands of years (Finney, 1994). Hokule'a is made out of modern materials, like fiberglass, but retained the size and shape of the ancient sailing canoes. She is over 62 feet long, 17.5 feet wide, with twin masts that reach 42 feet high (Finney, 1994). The sail area can total 700 sq feet, including the jib, main and mizzen sails. The entire canoe is held together by lashing, without nails.

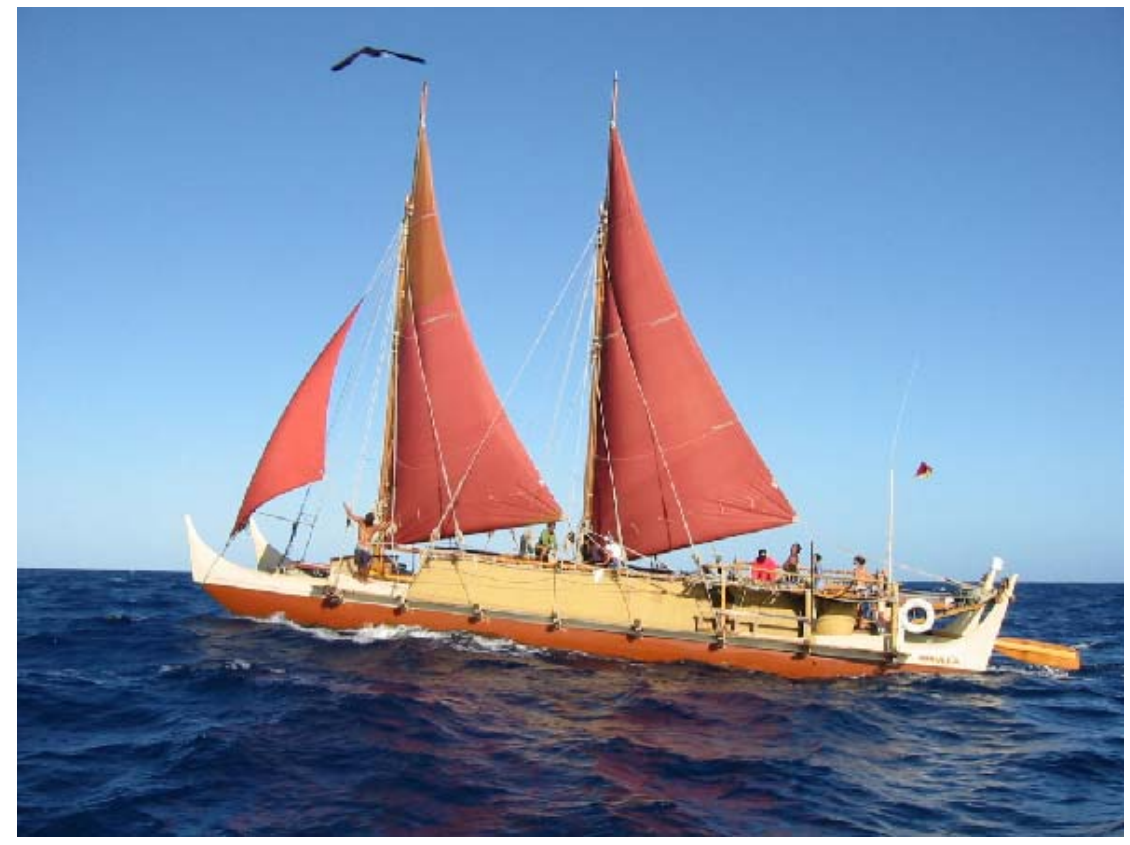

Figure 1

Hokule'a under sail

In May of 1976, Hokule'a sailed to Tahiti using the ancient techniques. Without the aid of modern instruments the captain, navigator and crew relied on the stars, winds, birds and sea swells to navigate 2,400 miles of open ocean to Tahiti (Finney, 1994). The voyage, which took thirty-three days to complete, proved that Native Hawaiians and Polynesians could sail vast amounts of ocean using traditional methods. Since then Hokule'a has traveled to all corners of the Polynesian triangle, as well as the west coast of the United States. It is estimated that
Hokule'a has sailed more than 100,000 nautical miles, since that first voyage in 1976.

Hokule'a has been sailing for 30 years, and its most recent voyage and project, "Navigating Change," brought together culture and science, the past and the present; in hopes of brining awareness and the immediate need to take action. Education is an important vehicle to help people understand and preserve their health and that of the environment. In 2004, in conjunction with several federal agencies, including the USFWS, NOAA, and with the support of PVS, a 
great endeavor was undertaken. Hokule'a sailed all the way from O'ahu to Kure Atoll, the last of the NWHI. Through "Navigating Change," students in elementary and secondary schools were taught the importance of preserving the NWHI, and were given a glimpse of what the main Hawaiian Islands once were like.

The 2004 Navigating Change's mission was to help spread the message that we must malama (care for) the land and sea; for these are what nourish the body and soul. To accomplish this we need to re-establish the link between the main Hawaiian Islands and the NWHI. Through foresight of our predecessors these islands have been under both federal and state protection. As a result, we have been able to maintain a relatively pristine environment for native plants, animals and marine creatures to propagate. It is our hope that we may use these islands as an example of what the main Hawaiian Islands should be like.

Hokule'a would travel approximately 2400 miles round trip, and took almost 2 months to complete. We documented the journey up the NWHI chain, and sent home information about the island chain, and the environment. Each day we had satellite phone conversations with students at local schools, news agencies, and even posted journals on websites. These pictures and updates would help bring to life a distant area so close to Hawai'i, which very few even knew existed. We were also had the opportunity to volunteer with some USFWS projects on some of the atolls along the way.

The crew consists of education specialists, scientists and culture experts, coming together to help send information home. During the voyage the crew is split into three-four hour shifts. The first shift is from 6 am to $10 \mathrm{am}$, the second is from 10 am to $2 \mathrm{pm}$, and third from $2 \mathrm{pm}$ to 6 pm. Your shift repeats again in 12 hours, so you are on shift for 4 hours and off for 8 hours. While on your shift you have the important responsibility of following the course set by the Navigator. Using the sails and steering sweep to help direct the canoe, your watch must work as a cohesive team to stay on the course. Holding an accurate course is one of the most important jobs a crew member can have, because every slight deviation from the intended course has to be memorized and accounted for by the Navigator. While on watch, one must make sure the rigging and the sails are properly adjusted and that the hulls are free of water. There are other general responsibilities like cooking and cleaning as well and manifesting supplies and taking care of your specific specialist role.

We provisioned for this trip by packing all the food and water we would need for the entire voyage, without accounting for any fish we may catch while sailing. As we approached the deeper waters of the NWHI we immediately noticed an increase in the number of fish. We caught fish almost everyday, but we only took as much as we could eat for the day. There was no refrigeration on board the voyage, so all food had to be consumed or else it would go to waste.

As we traveled up the NWHI from Nihoa, to Mokumanana, to French Frigate Shoals, to Gardner Pinnacles, the view and nature changed drastically from what we saw on the main Hawaiian Islands. The skies teemed with birds, so thick that at times they blocked the view of the sun. Schools of fish were ubiquitous; from the smaller reef fish to the much larger Jacks, including a wide variety of sharks.

We made a stop at Tern Island, and saw half a dozen Hawaiian Monk Seals basking in the sun. We passed turtle tracks in the sand so large that you thought it was a truck that came through and left those marks; and we saw birds so abundant and loud that you could barely hear your friend talking to you as you walked across the island. At this stop we helped set up fences over areas that had rusted metal piles jutting out from the sand, left as a reminder of when Tern was a refueling station during WWII. The fence was necessary so that turtles, birds and the seals would not hurt themselves on those areas. Once the project was accomplished we set sail again, continuing our journey. 


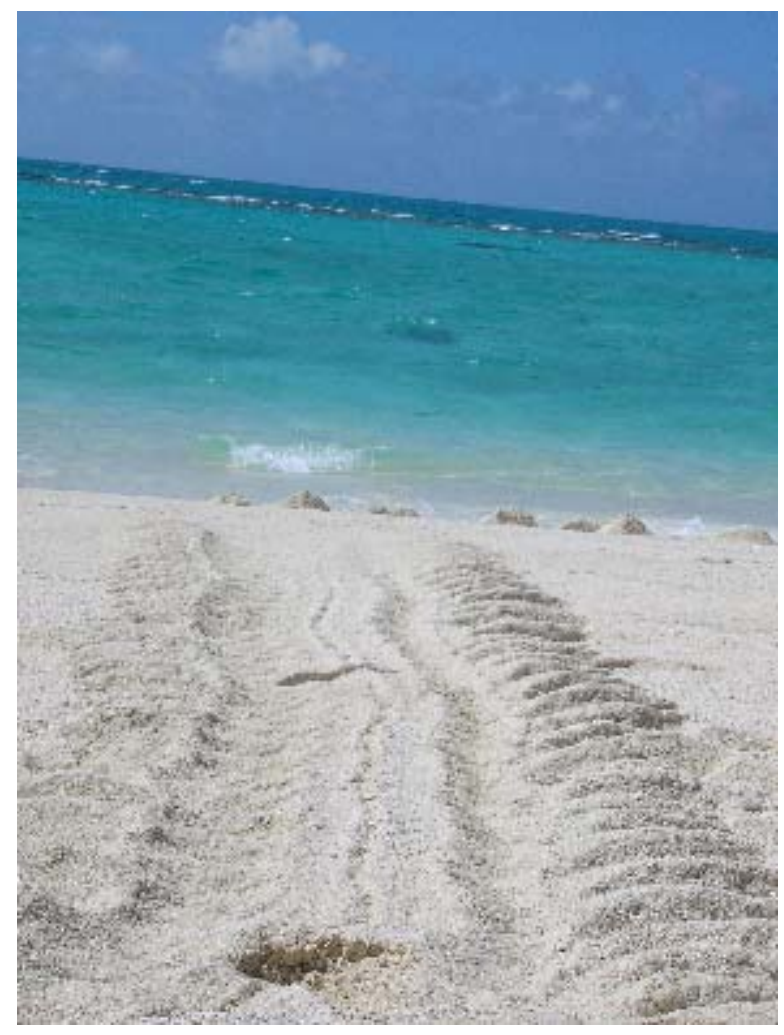

Figure 2

Tern Island turtle tracks

As we journey, and passed Maro reef, we could see the pastel green clouds being reflected from the lagoons around the atolls. Then we approached Laysan, we again were greeted by nature at its best. Laysan has a population of 610 people, from FWS and the National Marine Fishery Service. It is home to the Laysan duck and Laysan finches, both have their last known refuge here in the NWHI, and both are on the endangered species list. Again we saw the Hawaiian Monk Seals, and birds galore. However, as we traversed across the island, we noticed a juxtaposed view, for amongst all this life, you saw marine debris. At first you think that someone left it on the island when they visited, but remember, this is a Wildlife Reserve, no one can set foot unless permission is granted, and those who come would not dare to leave trash. What we saw were bottles strewn along the island, bundles of net as large as buses, floaters by the hundreds, all hazards to the wildlife. All of this marine debris came from fishing vessels, container ships, and a variety of other sources, sometimes floating for thousands of miles and for many years. As part of our visit, we helped break up the bus-sized nets, carried them several miles over the sand, and deposited at a designated sight for pick-up when the next Marine Debris Vessel arrives. We also helped transport plants for transplanting on other sides of the island and planted them, for they are important for some bird species. We also helped transport plants on the canoe to Midway Atoll, where they would be planted as part of the long term effort to re-locate some Layson ducks. 


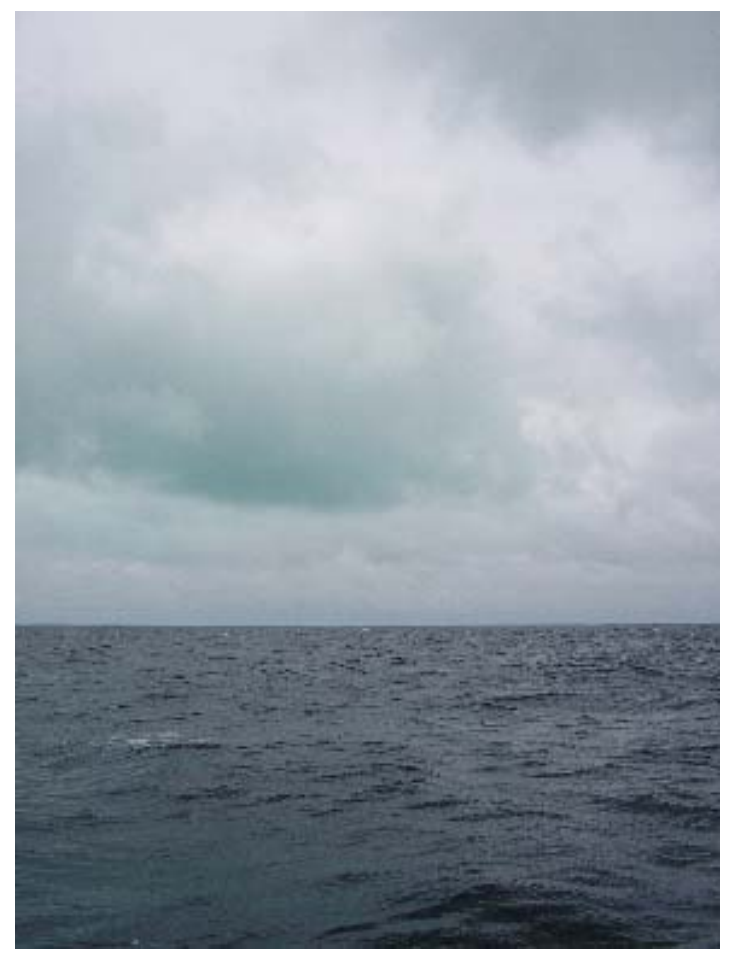

Figure 3

Maro Reef reflected in the clouds

Reluctantly, we left Laysan Island, and traveled past Lisianski Island up to Kure Atoll, eventually stopping at Midway Atoll. Midway is home to the famous WWII battle, which marked the strategic turning point of Japan's Pacific war,

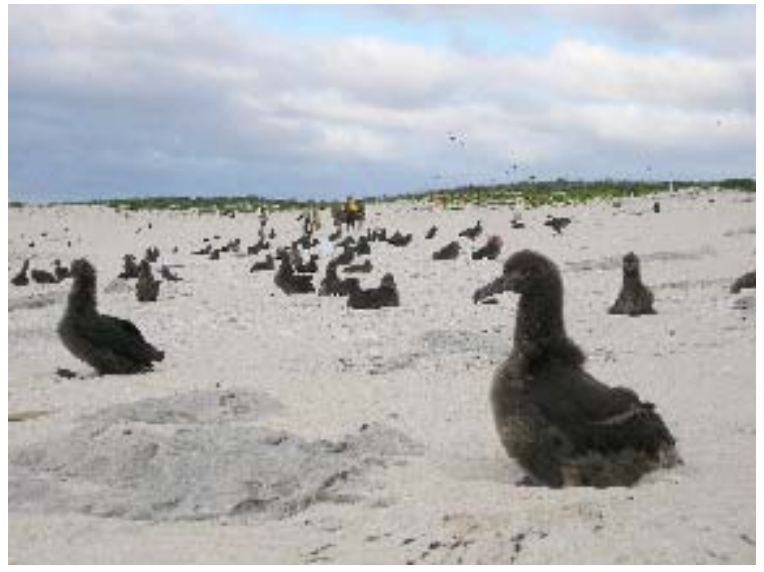

Figure 4 Fledglings nesting on Layson Island and now is home to many endangered species. This was the final stop for me, though only half of the journey. While on Midway, we helped deliver the plants sent from Laysan and have them replanted.

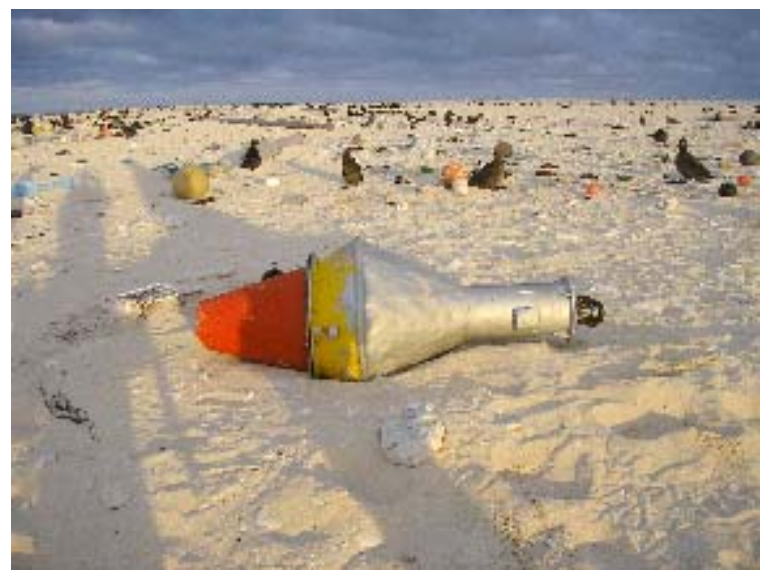

Figure 5

Fledglings amid Layson flotsam 


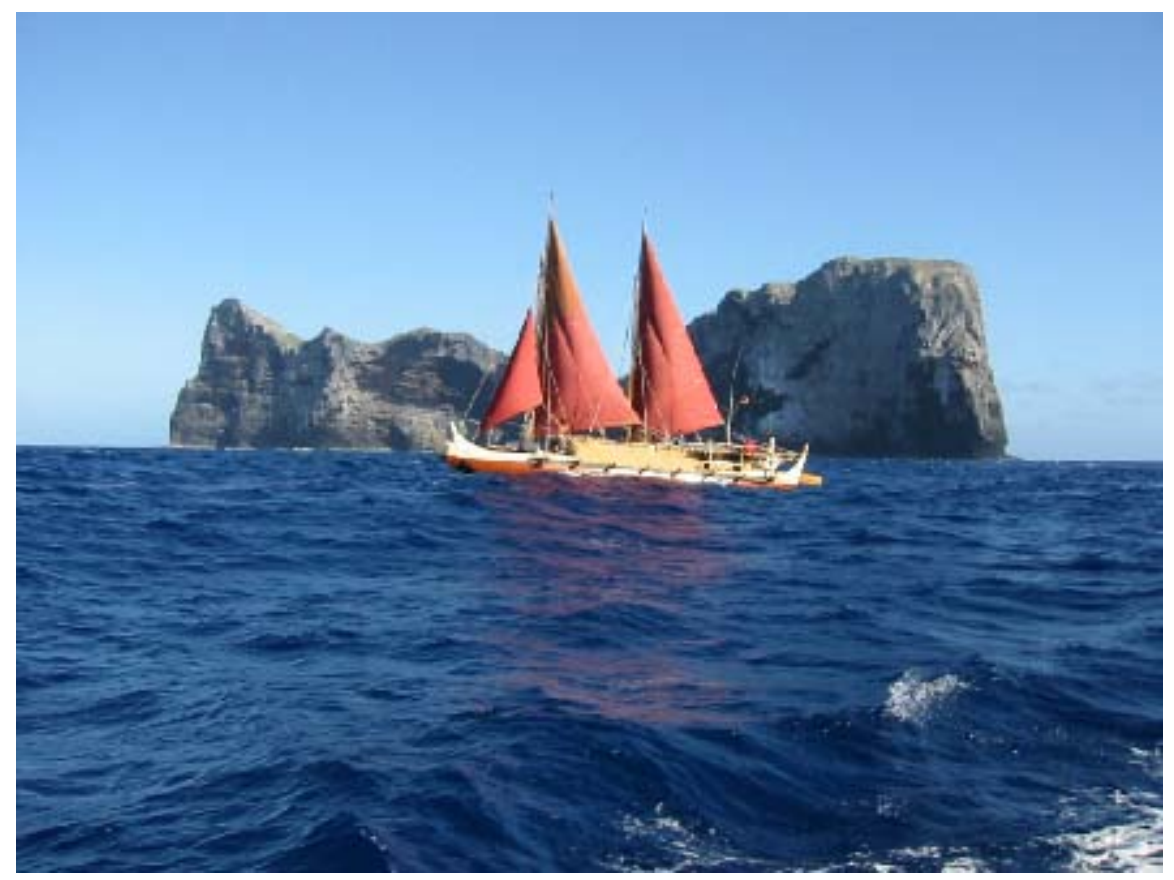

Figure 6

Hokule'a rounding Nihoa Island

\section{Health of Hawai'i's People and Land}

During the entire voyage we communicated with students in Hawai'i, heightening their awareness of the plight of the people and the land. The NWHI are a perfect example of what can be done to help save endangered species of birds, animals and plants. They show that if we take care of and protect our land, it will reflect on the health and wellness of the communities of that land. In the NWHI the birds and fish and plants are healthy and plentiful. They all live in a carefully balanced harmony. After visiting the NWHI it is clear that we live in the main Hawaiian Islands with very little balance.

Being on a canoe rather than sailing on a research ship put that idea of balance into perspective. Houkle'a, our own little island of sorts, has its own set of limited resources. We needed to be careful about how much food and water we used. The fact that we were eating a planned diet for thirty days with no fast food or alcohol showed on everyone's waistline too. The eight hours of physical activity of steering the canoe and setting sails helped a lot as well. For thirty days we lived on board as a family and in balance. Both of these values are important to living healthy. The hard part is expounding that microcosm to our daily lives at home back on land. The important part isn't just the voyage, it is what happens afterwards. Each of us came away with a deeper set of values and morals, and are committed to making Hawai'i a better, healthier place. The key is being able to find the value in the NWHI, not just in the biomass that it can give to the fish auctions around the world.

Comprehensive actions need to be taken, including removing fast food and sodas from schools, building bike paths, playgrounds, and improving insurance coverage (Brunhild, 2004). There also needs to be individually tailored programs that incorporate diet and physical activity (Taira, 2004). This needs to be supported with positive reinforcement and cultural adaptation of the message (Withy, Berry, Lee, and Yamada, 2005). If these things are done we can significantly decrease the 
number of deaths attributed to diet and physical activity alone (Mokdad, Markes, Stroup, and Gerberding, 2004). It has already been shown in Hawai'i that adapting a more traditional way of living in Hawai'i, one that integrates traditional lifestyle and diet, significantly improves health status (Shintani, Beckham, Tang, O’Conner, 1999). By doing so, participants were able to maintain weight loss for eight years after the course ended (Shintani, 1999).

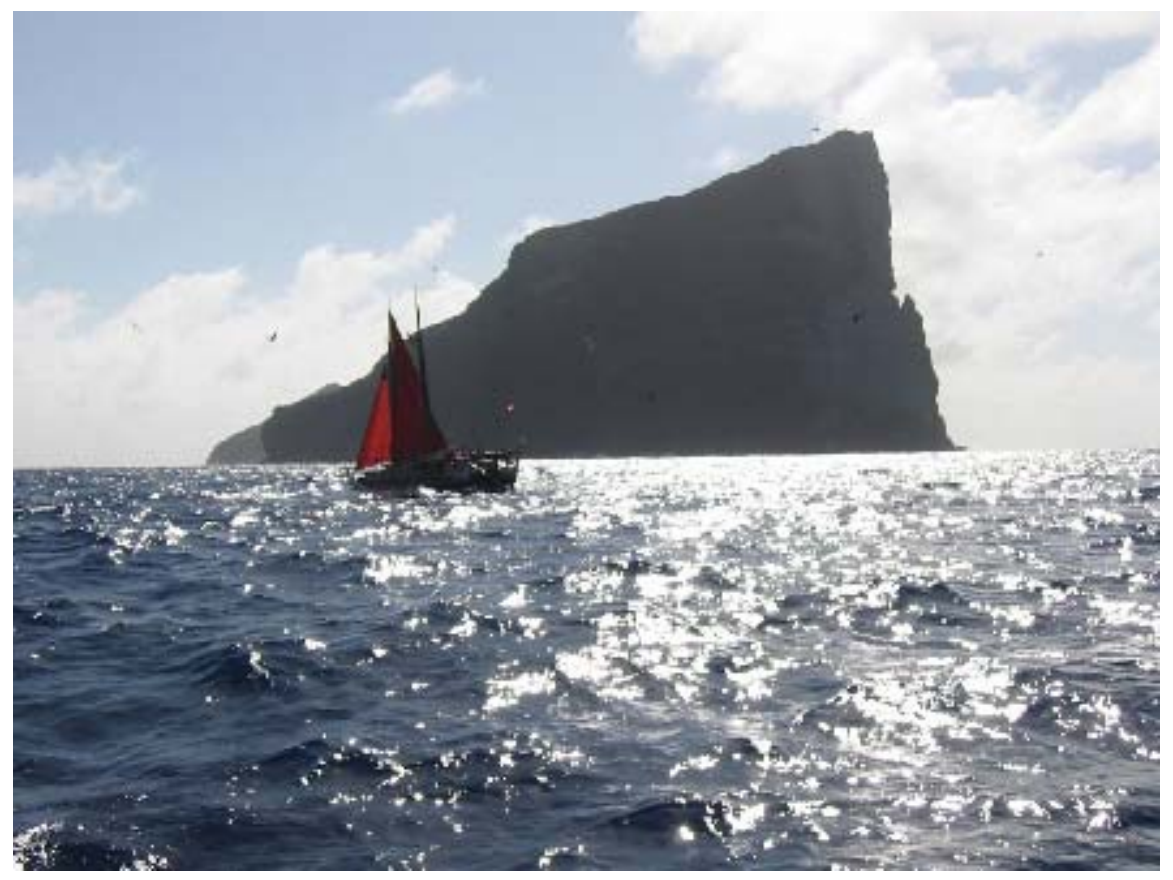

Figure 7

Hokulea sailing past Nihoa Island

\section{Conclusion}

It has been suggested that part of the health decline is due to cultural trauma, where the historical introduction of diseases, the relocation of the people, violation of religion and the breakdown of Hawaiian traditions results in the overall decline of health in Hawaiians (Cook, Withy, and Tarallo-Jensen, 2003). The solution to this problem is multifaceted, and requires complex negotiations of political sovereignty and land tenure. While a comprehensive solution may prove elusive, there are several aspects that can be immediately addressed by health care providers. We must: 1) understand the scope of the need; 2) increase and utilize resources; and 3) incorporate cultural healing (including voyaging, traditional crafts and skills, and religion).

More multi-agency and multi-disciplinary projects like Navigating Change must be started. Until we link science with culture within the health field, we will continue to live in a fragmented world. The plight of Native Hawaiians may be on the mend, with health care initiatives, increased programs at the public school level, and increased awareness amongst professionals and the public. Working together we can achieve a balanced ecology like the NWHI, improving the health of the environment and the people (Figure 8 and 9). 


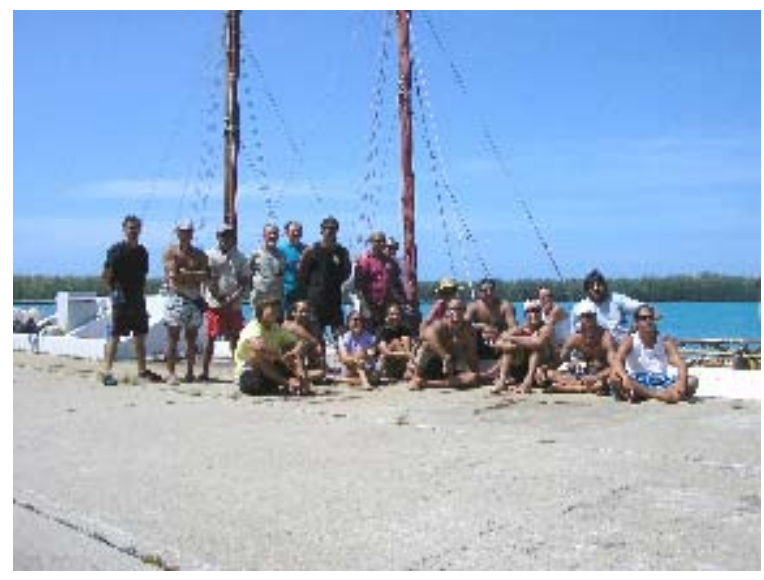

Figure 8

Hokule'a crew

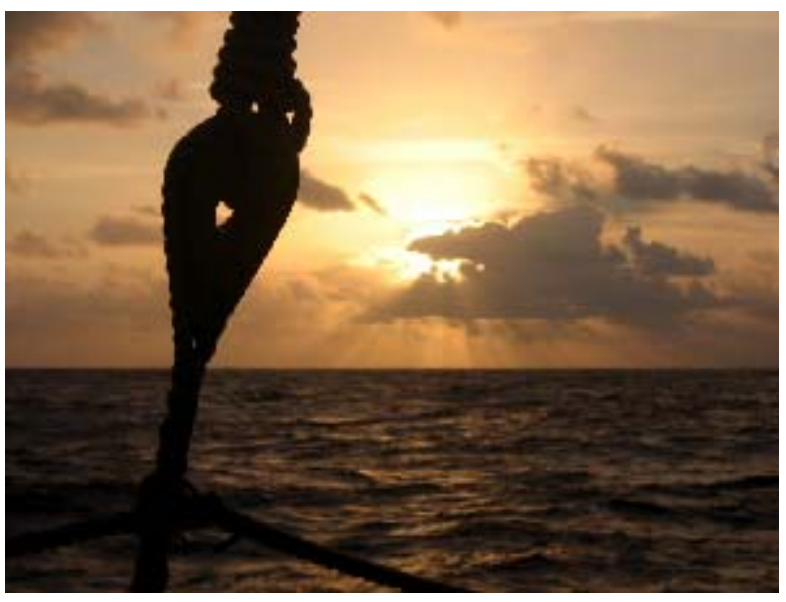

Figure 9

Sunset in the rigging

\section{References}

Cook, B., Withy, K., and Tarallo-Jensen, L. (2003). Cultural trauma, Hawaiian spirituality, and contemporary health status. Californian Journal of Health Promotion, 1(Sp Hawaii), 10-24.

Finney, B. (1994). Voyage of rediscovery. Berkley: University of California Press.

Halm, B., and Franke, A. (2004). Overweight and obesity, a worsening health problem particularly in children. Hawai'i Medical Journal. 63, 91-93.

Hawaii Department of Health (2004). Healthy Hawai'i initiative: Toward a healthy Hawai'i 2010: Checking the health of Hawai'i statewide. Honolulu, HI: Author.

Hope, B., and Hope, J. (2003). Native Hawaiian health in Hawai'i: Historical highlights. Californian Journal of Health Promotion, 1(Sp Hawaii), 1-9.

Kame'eleihiwa, L. (1992). Native land and foreign desires. Honolulu, HI: Bishop Museum Press.

Lewis, D. (1994). We, the navigators: The ancient art of land finding in the Pacific. Honolulu, HI: University of Hawai'i Press.

Mokdad, A., Markes, J., Stroup, D., and Gerberding, J. (2003). Actual causes of death in the US, 2000. The Journal of the American Medical Association, 291, 1238-1245.

National Oceanic and Atmospheric Association. (2003). Northwestern Hawaiian Islands: A resource guide. NOAA.

Rauzon, M. (2001). Isles of refuge: Wildlife and history of the Northwestern Hawaiian Islands. Honolulu, HI: University of Hawai'i Press.

Shehata, C., Freed, L., and Cann, R. (2001). Changes in native and introduced bird populations on Oahu: Infectious diseases and species replacement. Studies of Avian Biology, 22, 264-273.

Shintani, T., Beckham, S., Brown, A., and O’Conner, H. (2001). Ad libitum high carbohydrate, low fat multi-cultural diet for the reduction of chronic disease risk factors: obesity, hypertension, hypercholesterolemia and hyperglycemia. Hawai'i Medical Journal, 60, 69-73.

Shintani, T, Beckham, S., Tang, J., O'Conner, H., and Hughes, C. (1999). Waianae diet program: Long term follow up. Hawai'i Medical Journal, 58, 117-121.

Tiara, D. Gronley, K., and Ching, R. (2004). Patient characteristics, health status, and health-related behaviors associated with obesity. Hawai'i Medical Journal, 63, 150-154.

Withy, K., Berry, S., Lee, M. and Yamada, S. (2005). Efforts toward prevention in Hawai'i: Resources for providers to counsel patients about healthy lifestyle. Hawai'i Medical Journal, 64, 180-183. 


\title{
Acknowledgements
}

The authors would like to thank Nainoa Thompson, Bruce Blankenfeld, the Thompson Ohana, and all the Hokule'a crew members and volunteers, past and present, who help perpituate and make this dream possible. Photo Credits: Photos \# 1, 6, 7 and 9 and were taken by Na'alehu Anthony, Photos \# 2, 3, 4, 5 and 8 were taken by Cherie Shehata.

\author{
Author Information \\ Cherie Shehata, MD \\ Family Medicine Physician \\ Waianae Coast Comprehensive Health Center \\ AND \\ Assistant Clinical Professor \\ Department of Family Practice and Community Health \\ John A. Burns School of Medicine \\ University of Hawai'i \\ P. O. Box 235655 \\ Honolulu, HI 96823 \\ E-Mail: shehatac@yahoo.com \\ Na'alehu Anthony, MBA \\ Polynesian Voyaging Society \\ E-Mail: naalehu@mac.com \\ Gregory G. Maskarinec, PhD* \\ Associate Professor / Director of Research \\ Department of Family Practice and Community Health \\ John A. Burns School of Medicine \\ University of Hawai'i \\ AND \\ The Physician Center at Mililani \\ 95-390 Kuahelani Avenue \\ Mililani, Hawai'i 96789-1192 \\ The Physician Center at Mililani \\ 95-390 Kuahelani Avenue \\ Mililani, Hi 96789-1192 \\ Fax.: 808-627-3265 \\ Ph.: 808-627-7497 \\ E-Mail: gregorym@hawaii.edu \\ *corresponding author
}

